\title{
Neonatal Foot Length as Surrogate Marker for Prematurity: A Hospital Based Cross-Sectional Study in Central India
}

\section{Anju Kapoor and Triloki Nath Soni}

Department of Paediatrics, People's College of Medical Sciences and Research Centre, Bhanpur, Bhopal, Madhya Pradesh, India

\author{
Correspondence: \\ Anju Kapoor \\ Department of Paediatrics, \\ People's College of Medical Sciences \\ and Research Centre, \\ Bhanpur, \\ Bhopal, Madhya Pradesh, India \\ Email: dranjukapoor@gmail.com
}

DOI: $10.3126 /$ jnps.v40i3.29228

Submitted on: $2020-06-02$

Accepted on: 2020-10-06

Acknowledgements: None

Funding: Nil

Conflict of Interest: None declared

Permission from IRB: Yes

To cite this article: Kapoor A, Soni TN Neonatal foot length as surrogate marker for prematurity: A hospital based crosssectional study in central India. J Nepal Paediatr Soc. 2020;40(3):217-23.

\section{ABSTRACT}

Introduction: Neonatal mortality is higher in premature babies, more so when identification and intervention is delayed. This study was aimed to find out the effectiveness of foot length measurement, a simple and inexpensive method, for identifying premature babies at birth.

Methods: This cross sectional study was conducted on 514 hospital born neonates. Their foot length, birth weight, length and head circumference were measured and compared with gestational age assessed by new Ballard score.

Results: Amongst 514 newborns, $71.6 \%$ were term and $28.4 \%$ were preterm. Mean foot length in term and pre-term babies were $7.30 \mathrm{~cm}(\mathrm{SD} \pm 0.39)$ and $6.81 \mathrm{~cm}(\mathrm{SD} \pm 0.52)$ respectively (p value $<0.0001)$. Pearson's correlation coefficient between gestational age as assessed by new Ballard score and foot length, birth weight, length and head circumference all showed significant positive correlation in the decreasing order [maximum with foot length $(r=0.802)]$. Linear regression analysis for gestational age with foot length also had highest coefficient of determination $\mathrm{R}^{2}=$ $0.760(P<0.001)$. Foot length with cut-off $<6.83 \mathrm{~cm}$ has higher AUC (Area Under Curve) and is a good marker for predicting prematurity with a sensitivity of $94.57 \%$, and a specificity of $41.99 \%$.

Conclusions: Foot length measurement can be a good surrogate marker to predict prematurity as significant correlation is seen between it and gestational age assessed by new Ballard score.

Keywords: Gestational age; High risk newborn; Preterm

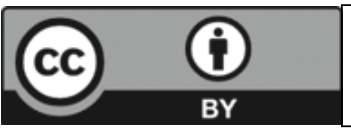

This work is licensed under creative common attribution 3.0 license 


\section{INTRODUCTION}

The preterm birth remains a serious problem globally. India is among the top five countries for number of preterm births and accounted for $23.4 \%$ preterm births globally in 2014. ${ }^{1}$ Although the neonatal mortality rate (NMR) in India has declined from 52 per 1000 live births in 1990 to 28 per 1000 live births in 2013, but the rate of decline has been slow; more so in early NMR than late NMR. ${ }^{2}$ The reason being high preterm births and their complications (43.7\%) making it the most common cause of neonatal deaths in India. ${ }^{3}$ Communitybased studies indicate that LBW weight infants are at 11 to 13 times increased risk of dying than normal birth weight infants and more than $80 \%$ of total neonatal deaths occur among preterm neonates and LBW babies. ${ }^{4}$ The coverage evaluation survey in 2009 (CES 2009) by UNICEF assessed the coverage of key interventions in antenatal, intrapartum and postnatal periods that can influence neonatal health. According to this survey, only a quarter of pregnant women had full antenatal check-up, $73 \%$ of women had institutional deliveries, one-third of neonates were breastfed within one hour after birth and less than half of the neonates received three postnatal visits by healthcare providers in the first ten days of life. ${ }^{5}$

No gold standard technique is currently available for precise gestational age assessment. During pregnancy, ultrasonic measurement and Naegele's formula using first day of last menstrual period (LMP) are being used for gestational age estimation while new Ballard score is used after birth. ${ }^{6}$ These approaches have their own strengths and weaknesses. LMP is reliable only if the menstrual cycles are regular and not influenced by use of hormonal contraceptives or maternal diseases. Antenatal ultrasonography also gives a variation of \pm 2 weeks in later part of pregnancy. Ballard scoring requires trained personnel. In developing countries where LMP estimates are unreliable due to illiteracy, poor availability of antenatal ultrasound and specialist for newborn care, simple method for assessing the GA of newborns is required to identify premature babies in remote areas. If we can identify and refer these at risk preterm newborns timely for specialised care, we can reduce early neonatal deaths. This can be achieved by inventing an inexpensive, fast, easy to use and acceptable screening tool for health workers.

Various anthropometric measurements can be performed to diagnose preterm status in newborns, such as circumferences of chest, abdomen, head, and calf. However, these measurements are influenced by subcutaneous fat. Such measurements take longer to perform, putting these infants at risk of hypothermia. To overcome this, present study was done to find out the effectiveness of measuring newborn foot length (FL) in identifying premature babies at birth without exposing the newborn to hypothermia.

\section{METHODS}

It was a cross sectional, observational and analytical study where data was collected from 514 newborns (term and preterm) delivered between Jan 2018 to June 2019 at a tertiary care hospital attached to a medical college. Study was started after taking due permission from Institutional Ethics Committee. Newborns were enrolled after written parental consent. Newborns with structural deformities, suspected or confirmed genetic abnormalities, neuromuscular conditions and congenital infections were excluded. Within 24 hours of birth, baby's FL was measured using a digital Vernier sliding calliper from the heel midpoint to the longest toe, without applying pressure on the soft tissue. The foot was positioned in lateral direction while holding the ankle. A finger was placed on the dorsum of foot to counteract the plantar grasp reflex which would have minimised the FL measurement. GA was assessed by new Ballard score which was also performed within first 24 hours of life. Other anthropometric variables measured were birth weight, head circumference and length of the baby using electronic weighing scale, non-stretchable measuring tape and infantometer respectively. FL measurement and Ballard scoring was performed by two post graduate residents independently.

Data was compiled using Microsoft excel while MedCal ${ }^{\circledR}$ (version 19.0.5) and SPSS (version 20.0) softwares were used for its analysis. D'Agostino skewness test was used to analyse the distribution 
of data. To investigate the linearity between two continuous variables, Pearson correlation was performed. Receiver operating characteristics curve (ROC - curve) analysis was used to define the cutoff value. Sensitivity, specificity and likelihood ratio for positive and negative tests were calculated at all cut-points for anthropometric variables. Weighted kappa was performed to find out interobserver agreement between measurements of categorical variable (GA assessment) and intraclass correlation coefficient (ICC) was performed to assess the agreement between measurements of continuous variable (FL measurement).

\section{RESULTS}

Present study enrolled 514 newborns; 281 (54.67\%) were male babies and $233(45.33 \%)$ were female babies; $71.6 \%$ were term and $28.4 \%$ were preterm babies. Descriptive statistics of anthropometric variables of recruited newborn are tabulated in Table 1. Mean FL in term newborn babies was 7.30 $\mathrm{cm}(\mathrm{SD} \pm 0.39)$ while it was $6.81 \mathrm{~cm}(\mathrm{SD} \pm 0.52)$ in pre-term babies and the difference was statistically significant $(\mathrm{p}<0.0001)$.

Pearson's correlation coefficient ( $r$ ) between GA and FL, birth weight, length and head circumference showed significant positive correlation, although maximum with FL (Table 2 and Fig 1). Linear regression analysis for GA with all anthropometric measurements is also shown in Table 2. The model had highest coefficient of determination $\mathrm{R}^{2}=0.761(\mathrm{p}<0.001)$ with FL. $\mathrm{R}^{2}$ of 0.761 means, in $76 \%$ of cases, GA can be predicted by the equation using foot length. Change in GA due to one $\mathrm{cm}$ change in FL is predicted to be 1.9163 week.

Sensitivity, specificity, predictive values (negative and positive), as well as likelihood ratios (negative and positive) were also determined (Table 3 ). The identification of preterm newborns with $\mathrm{FL}<6.83$ $\mathrm{cm}$ had a sensitivity of $94.57 \%$, which means that $94.57 \%$ of preterm newborns can be detected by a FL examination, and a specificity of $41.99 \%$ means that there is a $41.99 \%$ improbability of full term gestational age in newborns who have FL $<6.83$ $\mathrm{cm}$. For FL, the positive likelihood ratio $(+\mathrm{LR})$ value was 4.56 , indicating that the probability of preterm newborns having a $\mathrm{FL}<6.83 \mathrm{~cm}$ was 4.56 times greater than $\mathrm{FL}>6.83 \mathrm{~cm}$. The positive predictive value was also good $(81.2 \%)$, which means that for newborn FL $<6.83 \mathrm{~cm}$, the possibility of preterm gestational age was $81.2 \%$.

The Receiver Operating Characteristic (ROC) curve analysis was carried out to estimate gestational age through best possible cut-off of newborn's FL and also estimate the use of FL as a surrogate marker to distinguish between preterm and term babies (Fig 2). Since FL with cut-off $<=$ $6.83 \mathrm{~cm}$ has higher AUC than other variables it is a better marker for predicting prematurity (Figure 2).

Further in present study, newborn FL and GA assessment (by Ballard scoring system) was done by two different observers independently. Interobserver agreement (Weighted kappa) in assessing GA (by Ballard scoring) was found to be 0.89018 (95\% CI; 0.8641 to 0.9161$)$ while intra-class correlation coefficient (ICC) for measuring FL by two observers was $0.9671(95 \% \mathrm{CI} ; 0.9609$ to 0.9723).

\section{DISCUSSION}

We studied 514 newborns; $71.6 \%$ term and $28.4 \%$ preterm. Statistically significant difference was seen between Mean FL in the pre-term and term babies $[6.81 \mathrm{~cm}(\mathrm{SD} \pm 0.52)$ and $7.30 \mathrm{~cm}(\mathrm{SD} \pm$ $0.39)$ respectively $(\mathrm{p}<0.0001)]$. Pearson's

Table 1. Descriptive statistics of anthropometric variables of study population $(n=514)$

\begin{tabular}{|lrrrrr|}
\hline Variables (Overall) & Minimum & Maximum & Mean & $\mathbf{9 5 \%}$ CI & SD \\
\hline Birth weight (gm) & 1200.00 & 3600.00 & 2650.18 & 2617.43 to 2682.93 & 377.89 \\
Foot length (cm) & 5.15 & 7.98 & 7.16 & 7.12 to 7.20 & 0.48 \\
GA by new Ballard score (weeks) & 32.00 & 40.00 & 37.08 & 36.95 to 37.21 & 1.53 \\
Head circumference (cm) & 28.00 & 38.50 & 32.95 & 32.83 to 33.06 & 1.34 \\
Length (cm) & 38.00 & 51.50 & 47.50 & 47.36 to 47.64 & 1.65 \\
\hline
\end{tabular}

J Nepal Paediatr Soc Vol 40 Issue 3 Sep-Dec 2020 
Table 2. Pearson correlation and regression analysis between GA and anthropometric variables for study population

\begin{tabular}{|lllll|}
\hline \multirow{2}{*}{$\begin{array}{l}\text { GA (weeks) vs } \\
\text { Anthropometric Variables }\end{array}$} & \multicolumn{2}{c}{ Correlation Measurement } & \multicolumn{2}{c|}{ Regression Measurement } \\
\cline { 2 - 5 } & Correlation Coefficient (r) & P value & $\mathbf{R}^{\mathbf{2}}$ value & Regression equation (y) \\
\hline Foot Length (cm) & 0.802 & 0.001 & 0.761 & $\mathrm{y}=23.3581+1.9163 \mathrm{~A}$ \\
Birth Weight (gm) & 0.629 & 0.001 & 0.699 & $\mathrm{y}=31.1798+0.002228 \mathrm{~B}$ \\
Length (cm) & 0.611 & 0.001 & 0.585 & $\mathrm{y}=13.5497+0.4954 \mathrm{C}$ \\
Head Circumference (cm) & 0.581 & 0.001 & 0.525 & $\mathrm{y}=19.2398+0.5415 \mathrm{D}$
\end{tabular}

$y=$ Gestational age in weeks; $A=$ Foot length in $\mathrm{cm} ; B=$ Birth weight in grams; $C=$ Length in $\mathrm{cm} ; D=$ Head circumference in $\mathrm{cm}$

correlation coefficient between GA versus FL, birth weight, length and head circumference showed significant positive correlation in the decreasing order [maximum with FL $(r=0.802)]$. Linear regression analysis for GA with $\mathrm{FL}$ also had highest coefficient of determination $\mathrm{R}^{2}=0.760(\mathrm{P}<0.001)$. FL with cut-off $<6.83 \mathrm{~cm}$ has higher AUC and is good for predicting prematurity with sensitivity of $94.57 \%$, and a specificity of $41.99 \%$.

The results are drawn from overall newborn population while foetal growth and thus FL can be affected in SGA and LGA babies. ${ }^{7}$ Past studies have also documented significant correlation between foetal and neonatal foot length and gestational age. ${ }^{8,9}$ Study done in Tanzania has shown that FL measurement is helpful in identifying LBW, VLBW and preterm babies. ${ }^{10}$ Corresponding to GA of 37 weeks, the cut-off value of FL found by Srivastava et al. was $7.37 \mathrm{~cm}$ as compared to $6.83 \mathrm{~cm}$ in our study, probably due to geographical variation in different population. ${ }^{11}$

Tenali et al. reported that FL strongly correlated with gestational age in preterm AGA, SGA and term AGA babies $(<0.001)$ and correlation
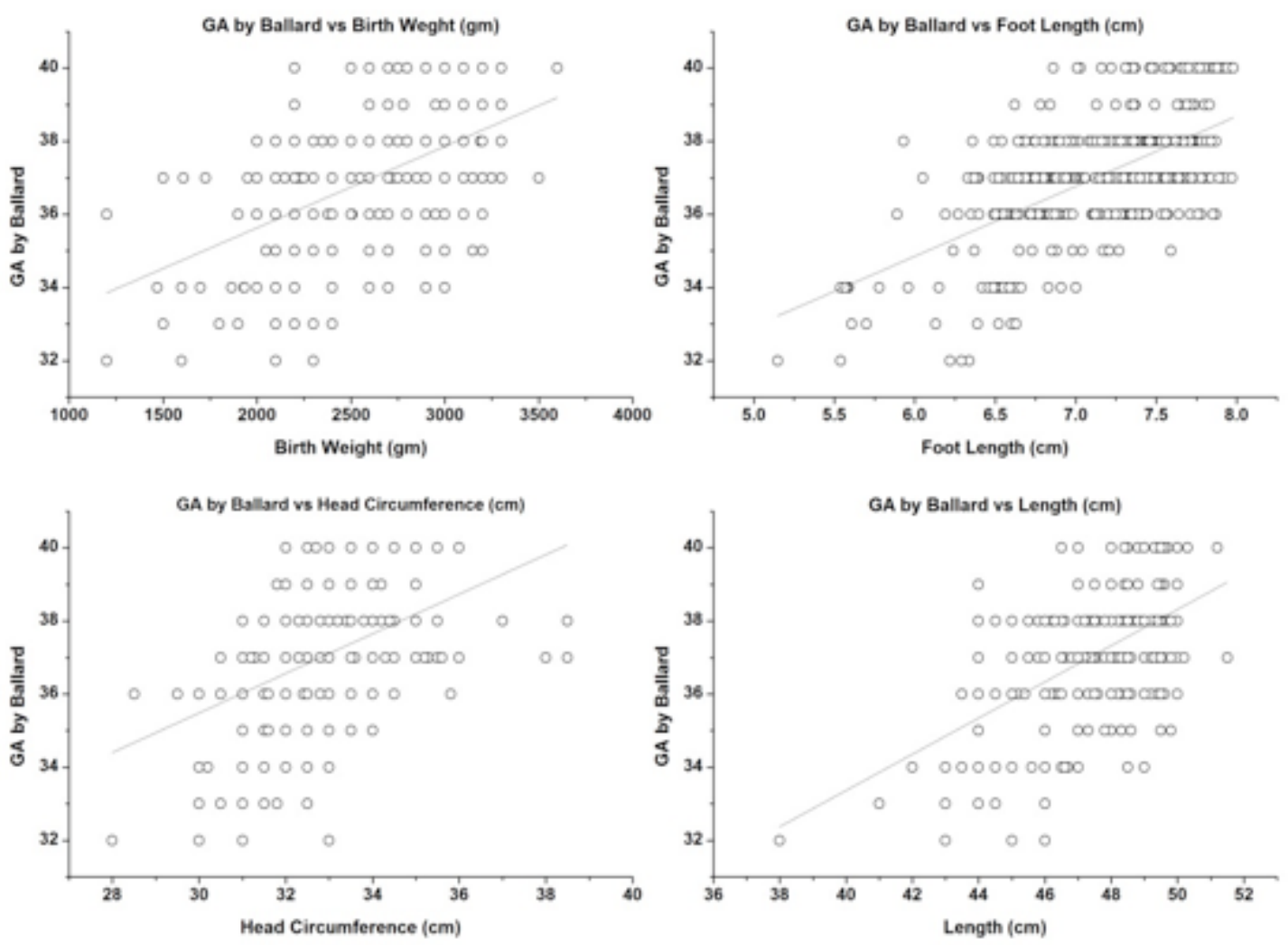

Figure 1. Scatter plot of GA and various anthropometric variables showing linear relationship 
Table 3. ROC curve analysis for GA and anthropometric variables, $(n=514)$

\begin{tabular}{|c|c|c|c|c|c|c|c|c|c|}
\hline Measurement & $\begin{array}{l}\text { Cut off } \\
\text { value }\end{array}$ & Sensitivity & Specificity & $\begin{array}{c}+ \\
\mathbf{L R}\end{array}$ & $\overline{L R}$ & $+\mathbf{P V}$ & $-P V$ & AUC & p Value \\
\hline $\begin{array}{l}\text { Foot length } \\
(\mathrm{cm})\end{array}$ & $<6.83$ & 94.57 & 41.99 & 4.56 & 0.15 & 81.2 & 73 & 0.776 & $<0.0001$ \\
\hline $\begin{array}{l}\text { Birth weight } \\
\text { (gm) }\end{array}$ & $<2300$ & 89.40 & 41.78 & 1.54 & 0.25 & 79.5 & 61 & 0.744 & $<0.0001$ \\
\hline $\begin{array}{l}\text { Head } \\
\text { circumference } \\
(\mathrm{cm})\end{array}$ & $<31.6$ & 76.84 & 35.62 & 1.47 & 0.14 & 78.8 & 73.2 & 0.745 & $<0.0001$ \\
\hline Length (cm) & $<45.4$ & 76.28 & 24.66 & 1.29 & 0.11 & 76.5 & 78.3 & 0.723 & $<0.0001$ \\
\hline
\end{tabular}

coefficient of foot length with gestational age was higher in preterms $(r=0.95)$. Study also documented that FL measurement was useful for quick estimation of gestational age in preterm and term neonates for early referral of newborns requiring special care and can even be done by basic healthcare personnel. ${ }^{12}$

Mukherjee et al. reported that foot length $<7.75 \mathrm{~cm}$ had $92.3 \%$ sensitivity and $86.3 \%$ specificity, for preterm newborn identification. Pearson's correlation test was used to assess a correlation coefficient. FL showed strong, positive, linear correlation with gestational age (0.869). ${ }^{13}$ Another study by Senthilkumar et al. demonstrated the positive correlation between FL and gestational age determined by LMP ( $\mathrm{r}=0.965)$ and ultrasound $(\mathrm{r}=$

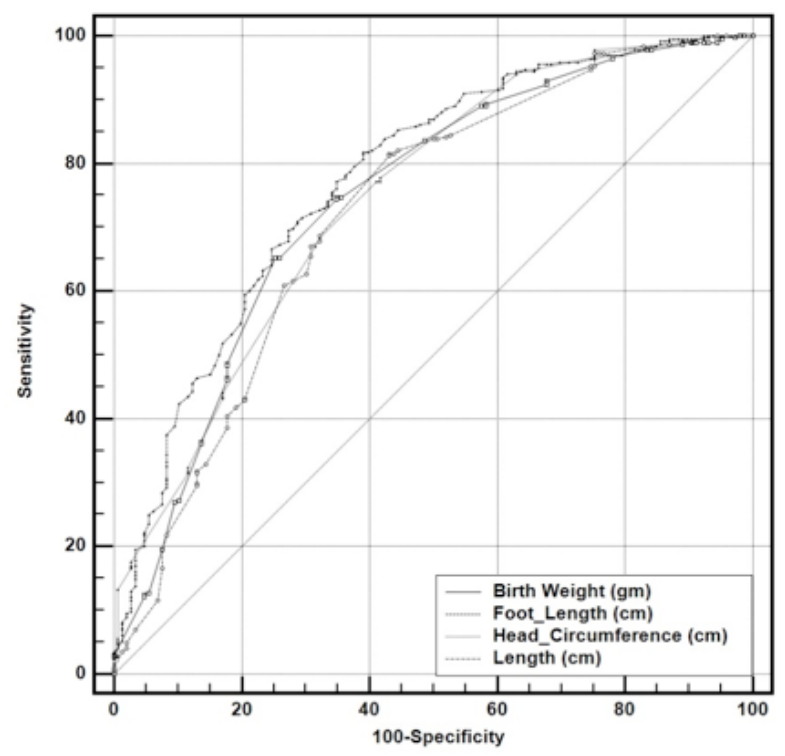

Figure 2. ROC curve analysis for GA and various anthropometric variables
0.964).$^{14}$ A study from rural parts of India enrolled over 1000 patients of 28 to 43 weeks GA to find the best parameter for GA assessment. Birth weight, FL, HC and crown-heel length of each case were measured. Similar to the findings of our study, they also documented that all the four anthropometric measurements correlated well with GA. Amongst anthropometric parameters individually, FL had maximum positive correlation $(\mathrm{r}=0.878)$ with $\mathrm{GA}$ followed by BW $(r=0.799)$, $\mathrm{HC}(r=0.766)$ and crown to heel length $(r=0.764)$ respectively. ${ }^{15}$ Contrary to our result, Lee et al showed that neonatal anthropometry had poor performance to classify preterm newborns. They concluded that newborn foot length $<75 \mathrm{~mm}$ had only $64 \%$ sensitivity and $35 \%$ specificity for diagnosing preterm status. ${ }^{16}$ Present study shows high intraclass correlation coefficient for measuring FL by two observers which has also been reported by other authors. ${ }^{17,18}$

As good correlation was seen between FL and GA, and FL is easy to measure with very little expertise and simple equipment, this can be used as a surrogate marker in identifying premature babies even at underprivileged and remote areas. The strength of our study is the adequate sample size. But there are few limitations also; being a hospital based study, the results are difficult to extrapolate in wider population. Although, present study reports high ICC for FL measured by two Paediatric residents, if it is to be used reliably as surrogate marker for prematurity by community birth attendants or paramedical staffs in remote areas, we should be able to demonstrate the same 
high level of agreement between Paediatric residents and these minimally trained staffs.

\section{CONCLUSIONS}

The study concludes that significant correlation is found between GA and FL measurement; therefore, it can be used as a surrogate marker for identifying premature babies. Timely identification and referral of these babies from remote areas will definitely improve their survival.

\section{REFERENCES}

1. Chawanpaiboon S, Vogel JP, Moller AB, Lumbiganon P, Petzold M, Hogan D, et al. Global, regional and national estimates of levels of preterm birth in 2014: a systematic review and modelling analysis. Lancet Glob Health 2018 30 Oct. DOI: doi.org/10.1016/S2214-109X(18)30451-0

2. Registrar General of India. Sample registration system (SRS) statistical report 2013. New Delhi: 2013. Available from http://censusindia.gov.in/vital_statistics/causesofdeath.html

3. Liu L, Johnson HL, Cousens S, Perin J, Scott S, Lawn JE et al. Global, regional, and national causes of child mortality: an updated systematic analysis for 2010 with time trends since 2000. Lancet. 2012;379(9832):2151-61. DOI: 10.1016/S0140-6736(12)60560-1

4. Bang AT, Bang RA, Baitule S, Deshmukh M, Reddy MH. Burden of morbidities and the unmet need for health care in rural neonates--a prospective observational study in Gadchiroli, India. Indian Pediatr. 2001;38:952-65. PMID: 11568371

5. United Nations Children Fund (UNICEF). Coverage Evaluation Survey 2009. UNICEF: New Delhi, India, 2009. Available from http://www.indiaenvironmentportal.org.in/files/National_Factsheet_30_August_no_logo.pdf

6. Ballard JL, Khoury JC, Wedig K, Wang L, Eilers-Walsman BL, Lipp R. New Ballard Score, expanded to include extremely premature infants. J Pediatr. 1991;119(3):417-23. DOI:10.1016/s0022-3476(05)82056-6.

7. Mercer BM, Sklar S, Shariatmadar A, Gillieson MS, D'Alton ME. Fetal foot length as a predictor of gestational age. Am J Obstet Gynecol. 1987;156:350-5. DOI: 10.1016/0002-9378(87)90282-1

8. Goldstein I, Reece EA, Hobbins JC. Sonographic appearance of the fetal heel ossification centres and foot length measurements provide independent markers for gestational age estimation. Am J Obstet Gynecol. 1988;159:923-6. https://doi.org/10.1016/S0002-9378(88)80172-8

9. Ebraheem M, Malik BA, Ali QM, Gameraddin M, Gareeballah A. Accuracy of foetal foot length measurement in estimation of gestational age and foetal weight in the third trimester of pregnancy. J Health Res Rev. 2018;5:142-6. DOI: $10.4103 /$ jhrr.jhrr_23_18

10. Marchant T, Jaribu J, Penfold S, Tanner M, Armstrong Schellenberg J. Measuring newborn foot length to identify small babies in need of extra care: a cross sectional hospital based study with community follow-up in Tanzania. BMC Public Health. 2010;10:624. Published 2010 Oct 19. DOI:10.1186/1471-2458-10-624.

11. Srivastava A, Sharma U, Kumar S. To study correlation of foot length and gestational age of newborn by new Ballard score. Int J Res Med Sci. 2015;3:3119-22. DOI: http://dx.doi.org/10.18203/2320-6012.ijrms20151147

12. Tenali ASL, Tenali RK. Study of foot length as an alternate measurement for assessment of gestational maturity in neonates. Int J Contemp Pediatr. 2019;6: 477-481. DOI:10.18203/2349-3291.ijcp20190684

13. Mukherjee S, Roy P, Mitra S, Samanta M, Chatterjee S. Measuring new born foot length to identify small babies in need of extra care: A cross-sectional hospital based study. Iran J Pediatr. 2013;23:508-12. PMID: 24800008 PMCID: PMC4006497

14. Senthilkumar K, Senthilprabhu R, Mythili B, Zacharias AM. Prediction of gestational age of newborn by measurement of foot length at birth. Int J Contemp Pediatr. 018;6:135. DOI:10.18203/2349-3291.ijcp20185196

15. Pandey VD, Singh V, Nigam GL, Usmani Y, Yadav Y. Fetal foot length for assessment of gestational age: A comprehensive study in north India. J Anat Soc India. 2016;65:19. DOI:10.1016/j.jasi.2016.08.068

16. Lee ACC, Mullany LC, Ladhani K, Uddin J, Mitra D, Ahmed P, et al. Validity of newborn clinical assessment to determine gestational age in Bangladesh. Pediatrics. 2016;138:20153303-e20153303. DOI:10.1542/peds. 2015-3303 
17. James DK, Dryburgh EH, Chiswick ML. Foot length--a new and potentially useful measurement in the neonate. Arch Dis Child. 1979;54(3):226-30. DOI:10.1136/adc.54.3.226.

18. Daga SR, Daga AS, Patole S, Kadam S, Mukadam Y. Foot length measurement from foot print for identifying a newborn at risk. J Trop Pediatr. 1988;34(1):16-19. DOI:10.1093/tropej/34.1.16 